Musa Yıldırım* and Dursun Özyürek

\title{
An Investigation of Wear Behaviors of AA7075 Al Hybrid Composites
}

https://doi.org/10.1515/htmp-2017-0016

Received February 8, 2017; accepted May 25, 2017

\begin{abstract}
This study investigates the wear behavior of $\mathrm{Al}$ hybrid composites produced by adding $4 \% \mathrm{Ti}$ and different amounts of $\mathrm{B}_{4} \mathrm{C}$ (ex situ) to the AA7075 alloy produced by powder metallurgy method in order to obtain $\mathrm{TiAl}_{3}$ (in situ) reinforcement phase. Different amounts of $\mathrm{B}_{4} \mathrm{C}(3 \%$, $6 \%$ and $9 \%$ ) were added to the $4 \%$ Ti added AA7075 alloy. Preformed parts were sintered in controlled atmosphere (argon) heat treatment furnace at $580^{\circ} \mathrm{C}$ for 4 hours and then cooled. After the sintering process, the samples were characterized with scanning electron microscopy, X-ray diffraction and density and hardness measurements. Wear tests of the samples were conducted at $1 \mathrm{~ms}^{-1}$ sliding speed, under $30 \mathrm{~N}$ load for 6 different sliding distances $(500-3000 \mathrm{~m})$. As a result of the study, the density of the AA7075 alloys, added 4\% $\mathrm{Ti}$ and different amounts of $\mathrm{B}_{4} \mathrm{C}$, was observed to decrease by the increasing amount of reinforcement elements. Also, the highest hardness value was measured for the $9 \% \mathrm{~B}_{4} \mathrm{C}$ added AA7075 alloy. Wear test results showed that the weight loss of the aluminum hybrid composites increased with the increasing sliding distance. On the other hand, it was observed that weight losses of composites decreased with increasing amount of $\mathrm{B}_{4} \mathrm{C}$.
\end{abstract}

Keywords: AA7075, hybrid composites, wear behaviors

\section{Introduction}

Aluminum composite materials (ACMs) constitute a widely preferred material group in many advanced material applications due to their low density and high performance. The poor wear resistance of aluminum alloys can be increased with addition of reinforcement phases [1-4]. The ratio, shape, size and type of the reinforcement phase are quite important for increasing the resistance of such materials.

*Corresponding author: Musa Yıldırım, Department of Manufacturing Engineering, Technology Faculty, Karabuk University, Karabuk Turkey, E-mail: musayildirim@karabuk.edu.tr Dursun Özyürek, Department of Manufacturing Engineering, Technology Faculty, Karabuk University, Karabuk Turkey, E-mail: dozyurek@karabuk.edu.tr
The properties of the reinforcement phase are directly related with the intended use of produced ACMs [5]. These materials are widely used in the production of machine parts, especially in automotive industry, and most of them are exposed to friction. In ACM production, hard ceramic reinforcements such as $\mathrm{Al}_{2} \mathrm{O}_{3}$ [6], $\mathrm{TiB}_{2}$ [7], $\mathrm{SiC}$ [8], $\mathrm{B}_{4} \mathrm{C}$ [9] and $\mathrm{TiO}_{2}$ [10] are generally used as reinforcement phase. These ex situ composite materials produced by adding hardceramic reinforcement phases stand out with their structural stability (especially in high temperature applications).

The most significant problem experienced with ex situ ACMs is the interface formed between the matrix and the reinforcement phase. The reinforcement phase can easily be removed with friction due to the interface formed between the matrix and the reinforcement phase during the production of ex situ ACMs. In such cases, the matrix cannot carry the load since the reinforcement phase does not perform its duty. In situ composite is the preferred production method to eliminate this problem in ACMs [1116]. The interest in these composites has been increasing since no interface is formed between the matrix and nanosized reinforcement phases in the matrix formed in situ by adding different elements to the alloy. The most significant disadvantage of these materials is their low performance in high temperature applications (due to high increase in temperature). However, matrix-reinforcement phase interface incompatibilities observed in ex situ are not seen in in situ composites. For this reason, this study investigates wear performances of hybrid ACMs produced by adding $4 \% \mathrm{Ti}$ and different amounts of $\mathrm{B}_{4} \mathrm{C}$ (ex situ) ceramic reinforcement phase in order to create in situ $\mathrm{TiAl}_{3}$ reinforcement phase in the matrix.

\section{Materials and method}

In this study, gas atomized 7075 aluminum alloy powders $(<100 \mu \mathrm{m})$ were used as matrix material. The chemical composition of gas atomized AA7075 aluminum alloy can be seen in Table 1.

Powders prepared by adding $4 \% \mathrm{Ti}(\leq 20 \mu \mathrm{m})$ and different amounts of $(3 \%, 6 \%, 9 \%) \mathrm{B}_{4} \mathrm{C}(\leq 10 \mu \mathrm{m})$ to AA7075 Al alloy were mixed in Turbula mixer at $67 \mathrm{rpm}$ for 45 minutes. Mixed powders were cold-pressed under 
Table 1: The chemical composition of gas atomized AA7075 Aluminum alloy.

\begin{tabular}{lccccccccc}
\hline Element & Zn & Mg & Cu & Fe & Si & Zr & Cr & Mn & Al \\
\hline Ağırlık (\%) & 5,48 & 2,58 & 1,568 & 0,549 & 0,403 & 0,0305 & 0,0125 & 0,014 & Kalan \\
\hline
\end{tabular}

$600 \mathrm{MPa}$ pressure and $\emptyset 12 \times 7 \mathrm{~mm}$ green compacts were produced. Green compacts were sintered in argon atmosphere at $580^{\circ} \mathrm{C}$ for 4 hours. After the sintering process, the samples prepared with standard metallographic procedures were etched with $95 \mathrm{ml}$ pure water, $2.5 \mathrm{ml} \mathrm{HNO3,} 1.5$ $\mathrm{ml} \mathrm{HCl}, 1 \mathrm{ml} \mathrm{HF}$ (Keller's) solution for 15-20 seconds. After the etching process, the samples were characterized. Scanning electron microscopy (SEM + EDS) (Zeiss-Ultra/ Plus [FEG] model) and X-ray diffraction n (XRD) (Rigaku D-MAX RIN-2200 Series X-RAY Diffractometer) were used for structural characterization. SHIMADZU hardness measurement device (HMV 0.5) was used to measure hardness. Density measurements were performed according to the Archimedes' principle. The mean value of five hardness measurements results is taken for each sample.

Wear tests were performed with standard pin-on disctype wear test device in accordance with ASTM-G99-05 standards. Prior to wear testing, the samples were grinded with 1200 grit sandpaper and polished using $6 \mu \mathrm{m}$ diamond paste to achieve the same surface quality for each sample. $1 \mathrm{~ms}^{-1}$ sliding speed, $30 \mathrm{~N}$ load and five different sliding distances $(500-3000 \mathrm{~m})$ were used in wear tests. The wear disc and sample surfaces were cleaned with acetone before wear tests. Worn samples were weighed on $1 / 10,000 \mathrm{~g}$ precision scale to determine weight losses. Once wear tests were completed, sample surfaces were examined under SEM. The equation used to calculate the wear rate can be seen in eq. (1).

$$
\mathrm{Wa}=\Delta \mathrm{m} / \text { M.s. } \rho
$$

where, Wa is wear rate, $\Delta \mathrm{m}$ is weight loss after the wear test $(\mathrm{g}), \mathrm{M}$ is the load weight $(\mathrm{N}), \mathrm{s}$ is sliding distance (m) and $\rho$ is density $\left(\mathrm{gr} / \mathrm{cm}^{3}\right)$.

\section{Results and discussion}

Figure 1 shows SEM images of hybrid ACMs produced by adding $4 \% \mathrm{Ti}$ and $9 \% \mathrm{~B}_{4} \mathrm{C}$ to the $\mathrm{AA7075} \mathrm{Al}$ alloy.

As seen in the microstructure SEM images in Figure 1, in situ (a) $\mathrm{TiAl}_{3}$ and ex situ (b) $\mathrm{B}_{4} \mathrm{C}$ reinforcement phases showed a homogeneous distribution in the Al- $\mathrm{Zn}-\mathrm{Mg}$ matrix and the structure. The images in Figure 1 also indicate that powder metallurgy is a reliable method to produce both ex situ and in situ composites. In addition, it is understood from the microstructure SEM images that $\mathrm{B}_{4} \mathrm{C}$ reinforcement phase added ex situ partially localized in the structure. $10 \mu \mathrm{m}$ or smaller powder sizes of $\mathrm{B}_{4} \mathrm{C}$, which was added to the alloy as the ex situ reinforcement element, allowed for localization of the reinforcement phase due to polarization (agglomeration) of powders. This case was pointed out in a previous study as well. Figure 2 shows XRD results of hybrid ACMs.

The XRD results given in Figure 2 show how certain reactions took place during the sintering process of hybrid composites between $\mathrm{Ti}$ and $\mathrm{B}_{4} \mathrm{C}$, which led to formation of new phases in situ. This new phase formed in the structure in situ is given in eq. (2).

$$
\mathrm{Ti}+3 \mathrm{Al} \rightarrow \mathrm{Ti} \mathrm{Al}_{3}
$$

$\mathrm{B}_{4} \mathrm{C}$ added to the AA7075 is a structurally stable material with a high melting temperature $\left(2723^{\circ} \mathrm{C}\right)$. The $\mathrm{B}_{4} \mathrm{C}$ phase is seen in the structure from different angles in the XRD results. Also, it is understood that $\mathrm{TiAl}_{3}$ phases was formed in the composite material in situ. It was reported in some previous studies that $\mathrm{TiAl}_{3}$ intermetallic phase was formed at temperatures between $500-600^{\circ} \mathrm{C}[11,17$, 18]. Reinforcement phases formed in the structure in situ

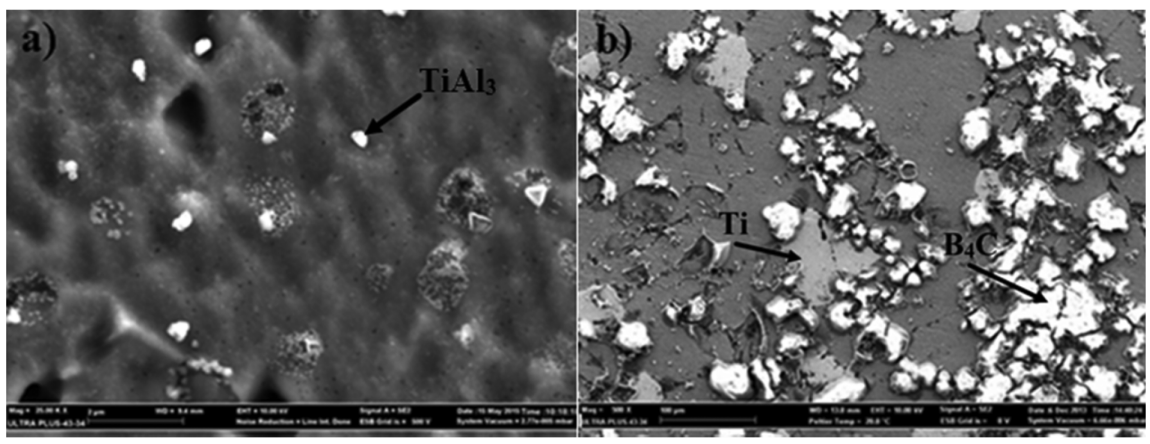

Figure 1: Microstructure SEM images of hybrid ACMs produced by adding $4 \% \mathrm{Ti}$ (a) and $9 \% \mathrm{~B}_{4} \mathrm{C}(\mathrm{b})$. 


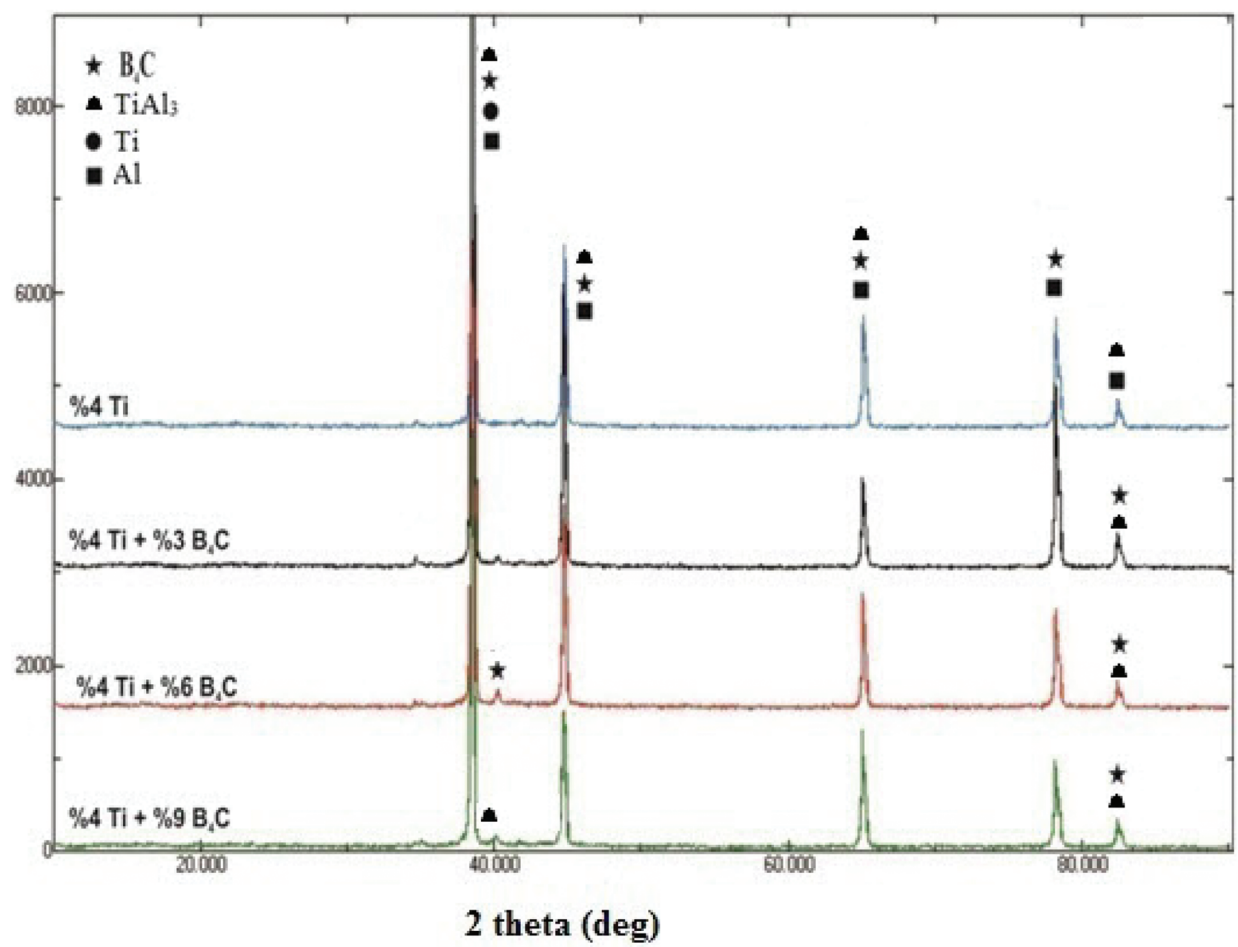

Figure 2: XRD results of hybrid ACMs. significantly contributes to the increase in strength of composites. The formation of in situ reinforcement phases during the sintering of ex situ composites produced by adding $\mathrm{B}_{4} \mathrm{C}$ improves properties of hybrid composites and the high strength factor expected from these composites. Also, the most significant contribution of phases formed in situ is that no matrix-reinforcement phase interface is formed unlike ex situ composites [19].

Final properties of hybrid composites depend on individual properties of selected matrix and reinforcement phases. In addition, the method used for production of hybrid ACMs depends on the nature of the matrix alloy and the reinforcement material, which are effective on final properties of ACMs. Figure 3 shows hardness and density changes in the hybrid composites produced using the powder metallurgy method.

It can be understood from hardness changes shown in Figure 3 that the hardness varied from 112 to $123 \mathrm{HV}$ with the addition of $4 \% \mathrm{Ti}$ and different amounts of $\mathrm{B}_{4} \mathrm{C}$ to the AA7075 alloy. The increase in the amount of ex situ $\mathrm{B}_{4} \mathrm{C}$ reinforcement phase and the $\mathrm{TiAl}_{3}$ phase formed in the structure in situ increased the hardness of hybrid composites. Density measurements showed that the increase in the amount of $\mathrm{B}_{4} \mathrm{C}$ decreases density. This is due to the lower density of $\mathrm{B}_{4} \mathrm{C}$ compared to the matrix phase of AA7075. It was reported in a previous study that
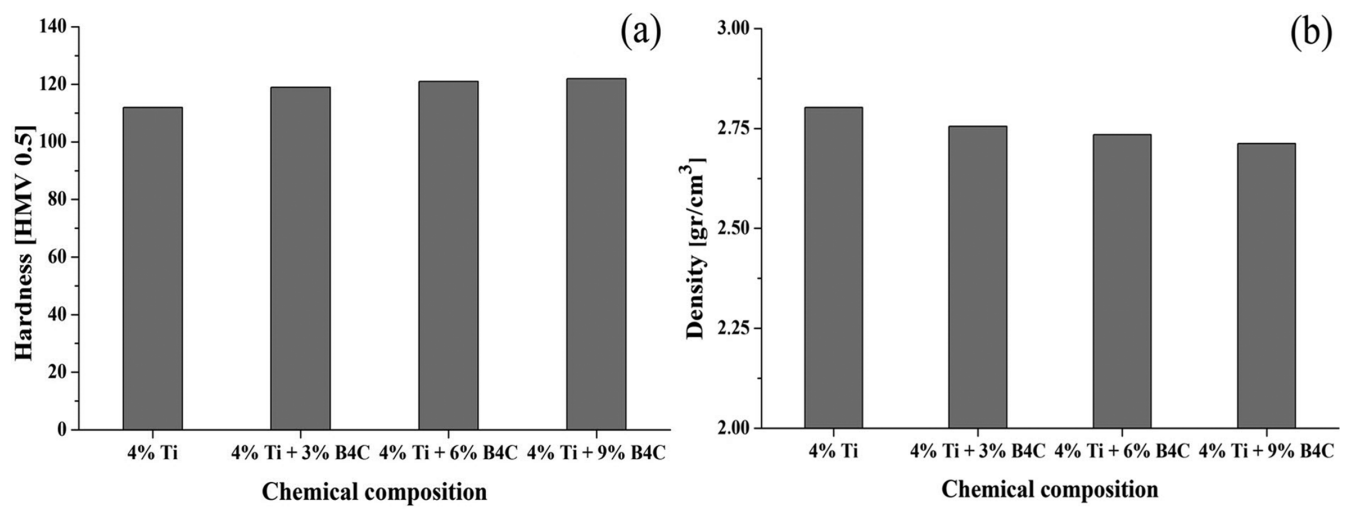

Figure 3: Hardness (a) and density (b) changes in the hybrid composites produced using the powder metallurgy method. 
the increased sintering time of in situ composites led to an increase in hardness and density [17]. In ex situ composites, on the other hand, the contribution of the reinforcement element in the structure depends on the amount added. For this reason, the increase in the hardness of $\mathrm{B}_{4} \mathrm{C}$ added composites changes in parallel with the increase in the amount of reinforcement phase added [20]. In addition, the increase in the ratio (wt\%) of reinforcement phase in composites produced ex situ results in an increase in hardness [21, 22,23, 24]. Figure 4 shows weight losses and wear rates of the hybrid composites after wear tests.

The weight loss results given in Figure 4 (a) show that the weight loss increased with increasing sliding distance in all composites. The weight loss decreased in all composites as the amount ( $\mathrm{wt} \%$ ) of $\mathrm{B}_{4} \mathrm{C}$ increased. It was also pointed out in previous studies that the increase in reinforcement phase resulted in a decrease in weight loss in ACMs produced ex situ $[6,7]$. The results obtained are confirmed by the hardness results in Figure 3. The lowest weight loss among ACMs was obtained for the hybrid composites produced by adding $4 \% \mathrm{Ti}$ and $9 \% \mathrm{~B}_{4} \mathrm{C}$. However, the weight loss increased rapidly after $2500 \mathrm{~m}$ especially for the hybrid composites produced by adding $4 \% \mathrm{Ti}$ and $6 \% \mathrm{~B}_{4} \mathrm{C}$. The reason for this sudden increase in weight loss is the particles detached from the sample surface during the sample-disk contact. There are two reasons for these fractures. The first reason is that the composites were produced using the powder metallurgy method. Such fractures may be observed in samples when bonds formed between powders during sintering are weak. The second reason is the interface formed between matrix-reinforcement phases in composite materials with metal matrix produced by adding $\mathrm{B}_{4} \mathrm{C}$ ex situ. Weak bonds formed between the matrix and the reinforcement element due to the interface result in fractures when forced. For this reason, reinforcement phases detach from the matrix due to breaking of weak bonds during wear tests with the increase in sliding distance, which results in an increase in weight loss. Wear rate results of ACMs given in Figure 4 (b) show that the wear rate increases with the sliding distance. The results obtained are supported by the weight loss results as well. This linear relationship between the weight loss and the wear rate is not observed in the
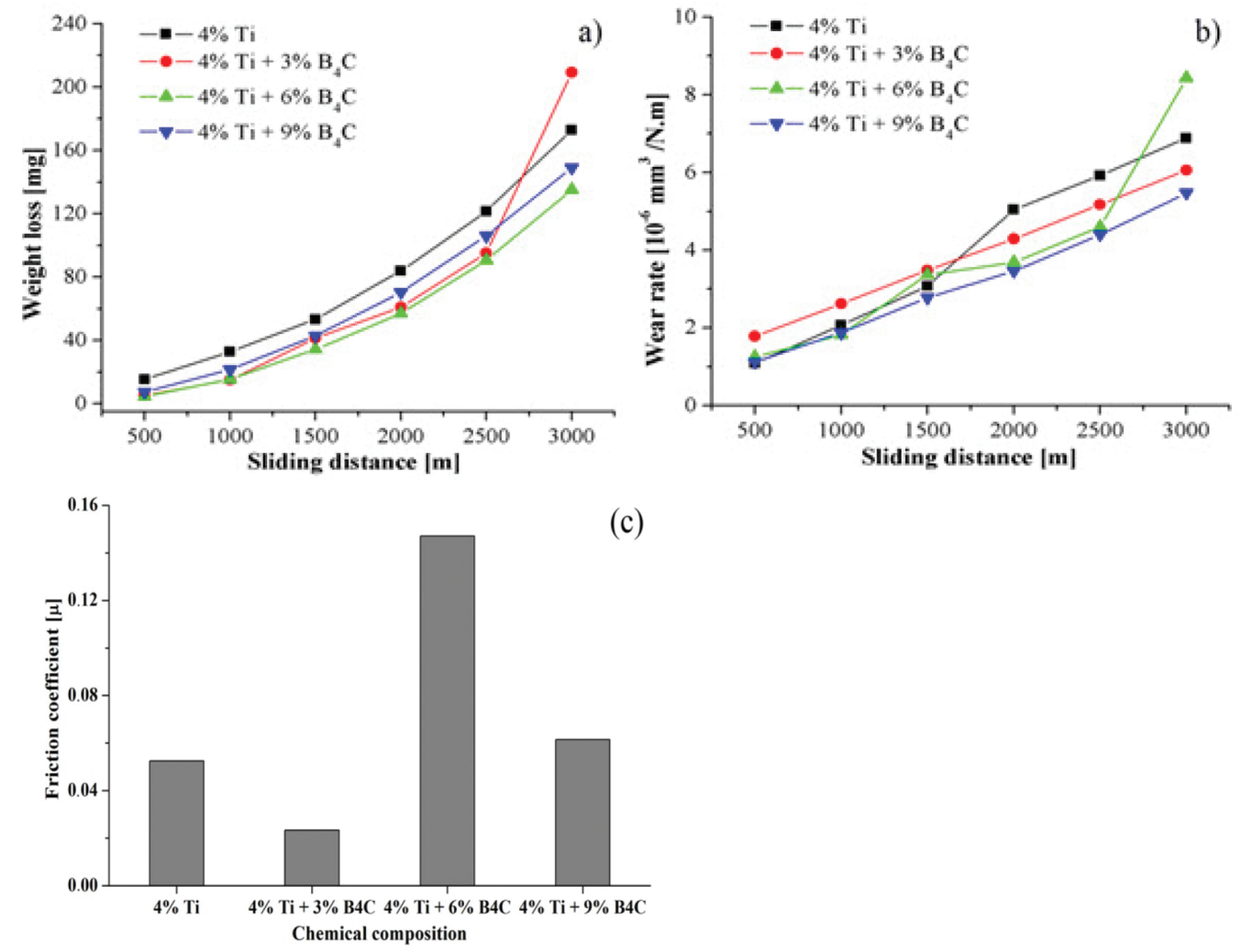

c)

Figure 4: Weight losses (a), wear rates (b) and friction coefficients (c) of hybrid composites produced using powder metallurgy under $30 \mathrm{~N}$ load. 
friction coefficient results given in Figure 4 (c). The lowest friction coefficient was obtained for the $4 \%$ (wt \%) Ti $3 \mathrm{~B}_{4} \mathrm{C}$ alloy. Hardness results given in Figure 3 show that graph followed a different route while we expected a decrease in friction coefficient with the increase in hardness. This is believed to be due to the interface effect between the matrix and the reinforcement phase which occurred during friction. $\mathrm{B}_{4} \mathrm{C}$ particles detached due to the weak interface bond between $\mathrm{B}_{4} \mathrm{C}$ and the matrix and were stuck between the disc and the sample leading to a different friction coefficient. Figure 5 shows the wear surface SEM images of ACMs produced by adding $4 \% \mathrm{Ti}$ and different amounts of $\mathrm{B}_{4} \mathrm{C}$.

Wear surface SEM images in Figure 5 clearly demonstrate the sliding direction. It is understood that the adhesive wear mechanism was predominant on wear surfaces in general. Micro chip particles detached from the wear surface reattached to the surface due to heat and damages such as scratches, smearing, flakes and tears occurred on wear surfaces of the samples. Deformation usually occurred on small microridges. As the amount (wt\%) of $\mathrm{Ti}$ and $\mathrm{B}_{4} \mathrm{C}$ in the structure increased, particles detached from the surface led to an increase in both the weight loss and the wear rate.

\section{Conclusion}

The results of the present study which investigates wear behaviors of in situ and ex situ hybrid composites are given below.

1. It was observed in microstructure examinations of composites produced by adding $\mathrm{Ti}$ and $\mathrm{B}_{4} \mathrm{C}$ to gas atomized AA7075 powders that reinforcement phases showed a homogeneous distribution in the structure.

2. In hybrid aluminum composites, the increase in the amount ( $w t \%)$ of $\mathrm{B}_{4} \mathrm{C}$ resulted in a decrease in density and an increase in hardness. Also, the weight loss decreased as the amount (wt\%) of $\mathrm{B}_{4} \mathrm{C}$ increased.

3. Among in situ aluminum composites, the lowest friction coefficient was obtained for the 4\% (wt\%) Ti 3 $\mathrm{B}_{4} \mathrm{C}$ alloy, whereas the highest weight loss was obtained for $4 \%$ Ti composites.

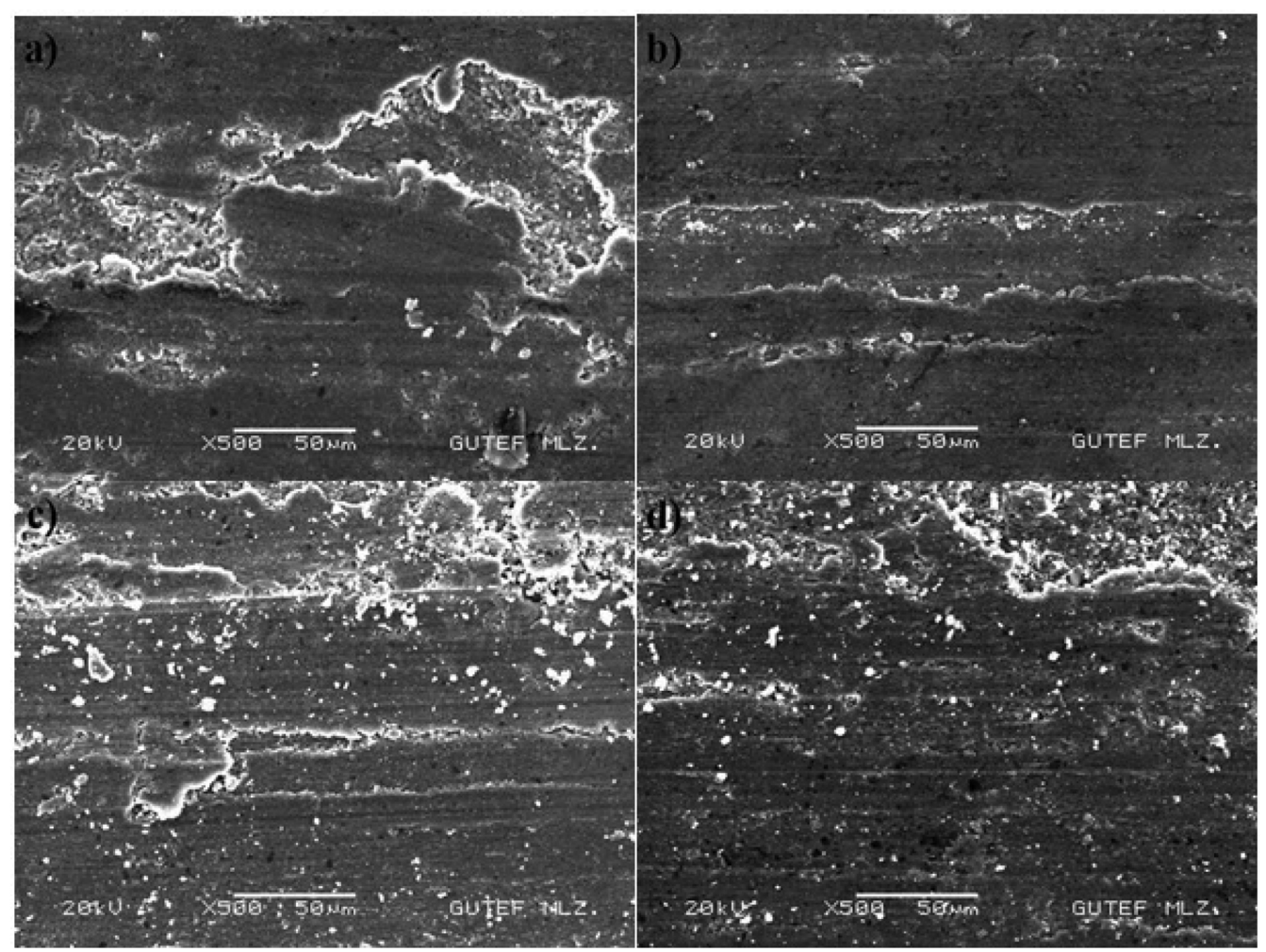

Figure 5: Wear surface SEM images of hybrid composites tested under $30 \mathrm{~N}$ load: $4 \% \mathrm{Ti} \mathrm{(a),} 4 \% \mathrm{Ti}+3 \% \mathrm{~B}_{4} \mathrm{C}(\mathrm{b}), 4 \% \mathrm{Ti}+6 \% \mathrm{~B}_{4} \mathrm{C}$ (c) and $4 \%$ $\mathrm{Ti}+9 \% \mathrm{~B}_{4} \mathrm{C}(\mathrm{d})$. 


\section{References}

[1] J. Singh and A. Chauhan, Ceram. Int., 42 (2016) 56-81.

[2] K.K. Alaneme and K.O. Sanusi, Eng. Sci. Technol. Int. J., 18 (2015) 416-422.

[3] G. Narasaraju and D.L. Raju, Mater. Today Proc., 2 (2015) 3056-3064.

[4] H. Aztekin, D. Özyürek and K. Çetinkaya, High Temp. Mater. Proc., 29(3) (2010) 169-178.

[5] P. Sharma, S. Sharma and D. Khanduja, J. Asian Ceram. Soc., 3 (2015) 240-244.

[6] D. Özyürek, S. Tekeli, A. Güral, A. Meyveci and M. Gürü, Powder Metall. Metall. Ceram., 49(5-6) (2010) 289-294.

[7] D. Özyürek and I. Çiftçi, Sci. Eng. Compos. Mater., 18(1-2) (2011) 5-12.

[8] D. Özyürek and S. Tekeli, Sci. Eng. Compos. Mater., 17(1) (2010) 31-38.

[9] A.T. Ozdemir and B. Bostan, Kovove Mater. Metal. Mater., 50(2) (2012) 89-95.

[10] J.H. Shin, H.J. Choi and D.H. Bae, Mater. Sci. Eng. A., 607 (2014) 605-610.

[11] D. Özyürek, T. Tunçay, H. Evlen and I. Çiftçi, Mater. Res., 18(4) (2015) 813-820.
[12] Y. Erarslan, Trans. Nonferrous Met. Soc. China., 23(2) (2013) 337-352.

[13] S. Ahmed, A.S.M.A. Haseeb and A.S.W. Kurny, J. Mater. Proc. Technol., 182(1-3) (2007) 327-332.

[14] C. Qiu, Y. Liu, L. Huang, B. Liu, W. Zhang, Y. He and B. Huang, Trans. Nonferrous Met. Soc. China., 22(11) (2012) 2593-2603.

[15] L. Niu, J. Zhang and X. Yang, Trans. Nonferrous Met. Soc. China., 22(6) (2012) 1387-1392.

[16] S. Aksöz, T. Ozdemir, R. Çalın, Z. Altınok and B. Bostan, J. Fac. Eng. Archit. Gaz., 28(4) (2013) 831-839.

[17] D. Özyürek, S. Tekeli, T. Tuncay and R. Yılmaz, Powder Metall. Metall. Ceram., 51(7-8) (2012) 491-495.

[18] E. Ghasali, M. Alizadeh, T. Ebadzadeh, A.H. Pakseresht and A. Rahbari, J. Mater. Res. Technol., 4(4) (2015) 411-415.

[19] S. Çam, V. Demir and D. Özyürek, Metals, 6(2) (2016) 34.

[20] R.P. Reed and M. Golda, Cryogenics, 37(5) (1997) 233-250.

[21] S. Aksöz, O. Bican, R. Çalın and B. Bostan, J. Eng. Tribol., 228(3) (2014) 312-319.

[22] R. Çalın and N. Cilasun, High Temp. Mater. Proc., 34(2) (2015) 131-139.

[23] M. Pul, G. Küçüktürk, R. Çalın and U. Şeker, J. Eng. Tribol., 225(2) (2011) 84-90.

[24] R. Çalın, M. Pul, O. Bican and G. Küçüktürk, Sci. Eng. Compos. Mater. (2015), DOI 10.1515/secm-2014-0109. 